\title{
The relationship between age and duration of asthma and the presence of persistent obstruction in asthma
}

\author{
C.K. Connolly, N.S. Chan* and R.J. Prescott ${ }^{1}$
}

Darlington Memorial Hospital, Darlington, Co. Durham and ${ }^{1}$ Medical Statistics Unit, Medical School, Teviot Place, Edinburgh, UK.

\begin{abstract}
Summary: Persistent obstruction was assessed in 630 asthmatic subjects by measurement after bronchodilator of the maximum potential peak flow rate and forced vital capacity. Persistent obstruction was directly related to duration of asthma. The fit was slightly better after logarithmic transformation, suggesting that the early stages of asthma may be as important as the later ones in the development of persistent obstruction. On multivariate analysis age was an additional factor in males, but made no significant difference to females. Atopy did not prove relevant. Measurements of peak flow suggested a more rapid deterioration in males of social classes III, IV and V than classes I and II. Although current smokers had lower peak flow rate and vital capacity than non-smokers, there was no evidence of a steeper decline in smokers than non-smokers suggesting that the effect of cigarette smoking was at most additive to that of duration of asthma.
\end{abstract}

\section{Introduction}

Asthma is, by definition, reversible airway obstruction. ${ }^{1}$ Nevertheless, persistent obstruction ${ }^{2}$ does occur in association with asthma in some subjects. This is particularly troublesome when patients become secondarily steroid resistant. ${ }^{3}$

Brown ${ }^{4}$ showed that the presence of persistent obstruction in asthmatics was more closely related to duration of asthma than to age, and suggested that its development was associated with previous poor control of wheeze. This study attempts to confirm and amplify these findings in subjects in the United Kingdom, and, by multiple regression, to see whether age influences the presence of persistent obstruction independently of duration of asthma. The subjects were also stratified by sex, atopic status, smoking habit and social class to see whether, within the confines of a cross-sectional study, these change the rate of development of persistent obstruction.

\section{Methods}

\section{Subjects}

All subjects 18 years and over, with a clinical diagnosis of asthma, documented by reversibility of

Correspondence: C.K. Connolly T.D., M.A., F.R.C.P. *Present address: Green Hospital, Auckland, New Zealand

Accepted: 6 January 1988 peak flow (PEFR), or forced expiratory volume in one second $\left(\mathrm{FEV}_{1}\right)$ of at least $20 \%$, attending regular consultative review clinics were recruited.

\section{History}

Duration of asthma was defined as the period since first onset, or after a symptom-free interval of at least 5 years. A history of asthma, recurrent bronchitis or 'chestiness' in childhood constituted childhood asthma. Social class was noted as defined by the Registrar General.

\section{Smoking}

Tobacco smoking was classified: (a) current smokers within the previous 3 months; (b) recent ex-smokers 3 months to 5 years; (c) longterm exsmokers more than 5 years; (d) passive smoker (cigarette smoker in household); (e) non-smoker: has never smoked more than 1 cigarette or other form of tobacco daily for more than 1 year.

The amount of cigarettes smoked was recorded in pack years. Carboxyhaemoglobin levels were measured in recent ex-smokers. If this was up to $1.5 \%$ they were accepted as ex-smokers. If greater than $2.5 \%$ they were reclassified as cigarette smokers. The smoking habit of those with levels between these values was regarded as unknown.

(C) The Fellowship of Postgraduate Medicine, 1988 
Atopy

Prick tests (Bencard) to at least 4 common allergens (grass pollen, D. pteronyssinus, Aspergillus fumigatus and cat) were performed. Subjects with a weal $3 \mathrm{~mm}$ greater than control were regarded as atopic; those with no response, non-atopic; those with intermediate readings, indeterminate.

\section{Pulmonary function}

Persistent obstruction was assessed by the difference between the best pulmonary function after treatment recorded within the previous year and predicted value for height, age and sex. ${ }^{5}$ Best or maximum function between $70 \%$ and $80 \%$ of predicted was accepted in patients maintained on inhaled sodium cromoglycate or inhaled corticosteroids with 4-hourly recording of peak flow for not less than 5 days. Maximum function of less than $70 \%$ required formal trial of steroids; prednisolone $30 \mathrm{mg} /$ day for not less than 5 days, with 4-hourly recording of PEFR to consistent results for the last 48 hours. Where these criteria had not been satisfied within the previous year, the maximum function was immediately assessed according to the above protocol. Both PEFR and forced vital capacity (FVC) were considered separately according to these rules.

\section{Statistical analysis}

Statistical analysis is based on standard parametric procedures. Multiple regression has been used to investigate the simultaneous effect of age and duration on variables indicating respiratory function. Analysis of covariance has been used to compare regression equations in different subgroups of patients and to estimate and compare adjusted mean levels in sub-groups, allowing for the effect of age and duration.

\section{Results}

Satisfactory estimation of maximum PEFR was obtained in 600 subjects and of FVC in 608. Two hundred and sixty eight had a formal trial of steroids and 336 four-hourly recordings of PEFR. Three hundred and ninety seven had a PEFR of greater than $80 \%$ and 409 an FVC of greater than $80 \%$ of predicted. Details of the subjects are shown in Table I. As anticipated, cigarette smoking was more frequent in males than females, but the overall mean FVC was similar in the two sexes. The mean maximum PEFR was greater in females than males $(P<0.0001)$ and this applies whether the standards of Cotes $^{5}$ or of Quanjer ${ }^{6}$ are used. ${ }^{7}$
Figure 1 shows that there is little correlation between age and duration of asthma (male $r=0.02$, female $r=0.14$ ). After the third decade, the mean duration was consistently about 20 years. As there were life-long asthmatics in all age groups, this was associated with an increasing proportion of asthma of short duration in the older age groups with relatively few subjects presenting between 10 and 30 years of age.

Table II presents the multiple regressions of maximum function (PEFR and FVC) on age and duration of asthma for males and females separately. Duration of asthma has the same effect on persistent obstruction in males and females, but there are sex differences with age. Asthma was less

Table I Details of subjects

\begin{tabular}{|c|c|c|}
\hline & $\begin{array}{c}\text { Males } \\
(310)\end{array}$ & $\begin{array}{c}\text { Females } \\
(320)\end{array}$ \\
\hline Age (years)(s.d.) & $51.4(15.8)$ & $51.9(16.9)$ \\
\hline Duration (years)(s.d.) & $18.4(16.4)$ & $20.5(15.9)$ \\
\hline$\%$ Childhood asthma & 41.4 & 40.0 \\
\hline$\%$ Atopic & 58.4 & 48.7 \\
\hline \multicolumn{3}{|l|}{ Smoking } \\
\hline$\%$ smoker & 20.3 & 10.9 \\
\hline$\%$ ex-smoker & 49.7 & 31.9 \\
\hline$\%$ never & 30.0 & 57.2 \\
\hline \multicolumn{3}{|l|}{ Social class } \\
\hline$\%$ I \& II & 29.4 & 33.5 \\
\hline$\%$ III & 38.0 & 36.9 \\
\hline$\%$ IV \& V & 32.6 & 29.7 \\
\hline Maximum PEFR (\%Pred)(s.d.) & $80.7(20.4)$ & $96.0(20.7)$ \\
\hline Maximum FVC (\%Pred)(s.d.) & $86.3(18.2)$ & $88.2(16.6)$ \\
\hline
\end{tabular}

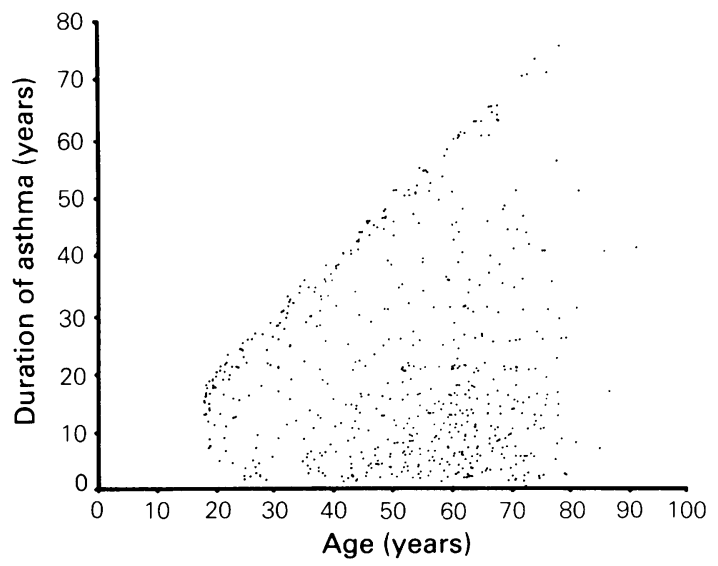

Figure 1 The relationship between age and duration of asthma. 
Table II Regression equations of maximum function on age and duration of asthma

\begin{tabular}{|c|c|c|c|c|c|c|c|c|}
\hline & \multirow[b]{2}{*}{ Sex } & \multirow[b]{2}{*}{$n$} & \multirow[b]{2}{*}{ Intercept } & \multirow[b]{2}{*}{ Age $(S E)$} & \multirow[b]{2}{*}{ Duration $(S E)$} & \multirow[b]{2}{*}{$R$} & \multicolumn{2}{|c|}{$\begin{array}{l}P \text { for equality } \\
\text { of slopes }\end{array}$} \\
\hline & & & & & & & age & duration \\
\hline PEFR & $\begin{array}{l}\mathbf{M} \\
\mathbf{F}\end{array}$ & $\begin{array}{l}290 \\
310\end{array}$ & $\begin{array}{l}107.6 \\
109.4\end{array}$ & $\begin{array}{l}-0.35(0.07) \dagger \\
-0.09(0.07)\end{array}$ & $\begin{array}{l}-0.50(0.06) \dagger \\
-0.43(0.07) \dagger\end{array}$ & $\begin{array}{l}0.50 \\
0.35\end{array}$ & 0.004 & 0.31 \\
\hline FVC & $\begin{array}{l}\mathbf{M} \\
\mathbf{F}\end{array}$ & $\begin{array}{l}302 \\
306\end{array}$ & $\begin{array}{r}104.2 \\
95.0\end{array}$ & $\begin{array}{l}-0.28(0.06) \dagger \\
-0.04(0.06)\end{array}$ & $\begin{array}{l}-0.21(0.06)^{*} \\
-0.25(0.06) \dagger\end{array}$ & $\begin{array}{l}0.31 \\
0.24\end{array}$ & 0.005 & 0.86 \\
\hline
\end{tabular}

Significance of regression coefficients: ${ }^{*} P<0.001 ; \dagger P<0.0001$; others $P>0.05$ (not significant)

Table III Regression equations of maximum function on age and log duration of asthma stratified by smoking

\begin{tabular}{llrrrrrrr}
\hline & Smoking & $n$ & Age $(S E)$ & $\begin{array}{c}\text { Log duration } \\
(S E)\end{array}$ & $R$ & $\begin{array}{c}P \text { for equality } \\
\text { of slopes }\end{array}$ & $\begin{array}{c}\text { Adjusted } \\
\text { means }(S E)\end{array}$ & $\begin{array}{c}P \text { for equality } \\
\text { of adjusted means }\end{array}$ \\
\hline PEFR & & & & & & & & \\
Males & Non- & 85 & $-0.27(0.11)$ & $-7.0(1.9)$ & 0.42 & & $85.2(2.0)$ & \\
& Ex- & 137 & $-0.33(0.13)$ & $-9.3(1.4)$ & 0.55 & 0.57 & $81.0(1.5)$ & 0.004 \\
& Current- & 58 & $-0.53(0.15)$ & $-7.8(1.9)$ & 0.56 & & $75.2(2.2)$ & \\
Females & Non- & 176 & $0.00(0.09)$ & $-6.3(1.6)$ & 0.28 & & $96.9(1.5)$ & \\
& Ex- & 93 & $-0.38(0.15)$ & $-6.6(1.7)$ & 0.44 & 0.09 & $96.9(2.1)$ & 0.26 \\
& Current- & 36 & $-0.44(0.18)$ & $-3.8(2.8)$ & 0.42 & & $91.1(3.3)$ & \\
\hline
\end{tabular}

reversible in older than younger men, but there were no differences in females with age. The effect of using other functions of age and duration of asthma were tried, but only logarithmic transformation of duration of asthma produced a marginally better fit, particularly in men. The conclusions were qualitatively unaltered, but the slight improvement on logarithmic transformation suggests that events early in the clinical course of asthma are at least as important as later events in influencing the development of persistent obstruction. As there was a slightly better fit, log duration of asthma was used when the regression equations were stratified by atopy, social class and cigarette smoking. Atopic status did not prove relevant. Peak flow suggested that age had a greater effect on persistent obstruction in the lower social classes in male subjects only $(P<0.0007)$. In nonsmokers, duration of asthma was more important than age in determining the presence of irreversible disease, whilst in smokers age is more important (Table III). Similar overall regression coefficients show that the combined effect of age and duration of asthma results in a similar overall rate of deterioration in smokers and non-smokers. However, the generally lower adjusted means, which apply to FVC as well as to maximum PEFR, show that smokers have worse function for the same age and duration of asthma.

\section{Discussion}

This study was conducted without additional help during routine clinical work. The possibility of giving corticosteroids to all subjects was considered but this was not ethically justified in asthmatics who were totally reversible to a normal peak flow rate and normal shaped spirogram. Seasonal variation was reduced by using maximum figures recorded over a full year. The ideal of identical treatment could not be obtained, so the study presents the results of appropriate treatment using the same results for all subjects. As those with better pulmonary function are more likely to have been under treated, any error arising from inconsistencies in maximum therapy is likely to reduce the significance of the findings presented here, rather than produce invalid associations. It has previously been shown that there is a tendency for some asthmatics to develop persistent obstruction with time ${ }^{4,8,9}$ particularly as assessed by their response to corticosteroids. Brown suggested this was more likely to happen with poor management. He showed a weaker relationship with age, but did not do a multivariate analysis. The results presented here confirm the effect of duration of asthma on reduced response to maximal treatment. Multivariate analysis shows age makes no further significant contribution in women whilst 
in men the effects of age and duration of asthma are similar.

Dutch studies suggest that atopy contributes to the deterioration of pulmonary function with time. ${ }^{10}$ It is possible that this apparent relationship with atopy is due to an incidental association between atopy and bronchial lability, ${ }^{11}$ and so would be manifest in all asthmatics irrespective of atopic status. Bronchial lability at presentation did prove to be a marker of potential persistent obstruction in bronchitics defined by sputum production. $^{12}$ If these 'bronchitics' included asthmatics in whom a bronchial inflammatory component is manifest by sputum production, then asthmatics with a bronchial inflammatory element from the start might be at particular risk of developing persistent obstruction. The 1946 Medical Research Council cohort study demonstrates an association between reduced PEFR and childhood respiratory symptoms. ${ }^{13}$ Here childhood asthma is a significant additional dependent variable with the partial correlation coefficient, suggesting that persistent obstruction is approximately $5 \%$ worse in those with a history of childhood asthma. ${ }^{14}$ With the slightly better fit for log duration of asthma, this study and the above suggest that events early in the course of asthma may be important in determining the later development of persistent obstruction.

The small differences between the social classes are concentrated in males, but class was determined by the senior male member of the household and there may be greater environmental exposure in males. The effect of cigarette smoking was greater on the adjusted mean of maximum pulmonary function than on the rate of deterioration with age and duration of asthma. Although the most severely affected smokers may have been excluded from the study as manifesting only 'fixed obstruction', and periods of cigarette smoking and asthma do not necessarily coincide, the results do suggest that smoking is at most additive, and certainly not synergistic, to the effect of asthma on the development of persistent obstruction.

Questions are raised here which can only be satisfied by a longitudinal study. Persistent obstruction certainly develops in a proportion of asthmatics, but only continuous observation on the same individuals can determine this proportion. A prospective study into the prognosis of adult asthma using these subjects with the data presented here as a baseline is to be undertaken.

\section{Acknowledgements}

We wish to thank Mr A. McNay, Regional Statistician, Northern Regional Health Authority for original recording of the data and Mrs C. Edwards, Miss C. Corner, Miss B. D'Arcy and Miss S. Tate for the typing of the manuscript.

\section{References}

1. Ciba Foundation. Terminology, definitions and classification of chronic pulmonary emphysema and related conditions. Report of the conclusions of the CIBA Guest Symposium. Thorax 1959, 14: 286-299.

2. Fletcher, C.M. \& Pride, N.B. Definitions of emphysema, chronic bronchitis, asthma and airflow obstruction: 25 years on from the CIBA Symposium. Thorax 1984, 39: 81-85.

3. Carmichael, J., Paterson, I.C., Diaz, P., Compton, G.K., Kay, A.B. \& Grant, I.W.B. Corticosteroid resistance in chronic asthma. Br Med J 1981, 282: 1419-1422.

4. Brown, P.J., Greville, H.W. \& Finnicaine, K.E. Asthma and irreversible airflow obstruction. Thorax 1984, 39: 131-136.

5. Cotes, J.E. Lung Function, 4th ed. Blackwell, Oxford, 1978.

6. Quanjer, P.H. (compiler and editor). Standardised lung function testing. Interim report Working Party 'Standardisation of Lung Function Tests'. European Community for Coal and Steel.

7. Connolly, C.K. Standards for pulmonary function in clinical practice, Cotes or European. Eur J Respir Dis 1986, 67(Suppl. 146): A39.

8. Irnell, L. A study of bronchial asthma. Acta Med Scand 1964, 176: 1-170.
9. Loren, M.L., Leung, P.K., Tooley, R.L., Chai, H., Bell, T.D. \& Buck V.M. Irreversibility of obstructive changes in severe asthma in childhood. Chest 1978, 74: 126-129.

10. Van der Lende, R., Kok, T.J., Reig, R.G., Quanjer, P.H., Schouten, J.P. \& Orie, N.G. Increase in VC and FEV with time indicators for effects of smoking and air pollution. Bull Eur Physiopathol Respir 1981, 17: 775-792.

11. Woolcock, A.J., Peat, J.K., Salome, C.M. et al. Prevalence of bronchial hyperresponsiveness and asthma in rural population. Thorax 1987, 42: 361-368.

12. Campbell, A.H., Barter, C.E., O’Connell, J.M. \& Huggins, R. Factors affecting the decline of ventilatory function in chronic bronchitis. Thorax 1984, 40: 741-748.

13. Davies, J.M.C., Britten, N. \& Colley, J.R.T. Early respiratory experience and subsequent cough and peak expiratory flow rate in 36 year old men and women. Br Med J 1987, 294: 1317-1320.

14. Connolly, C.K. Persistent obstruction in asthmatics: time and social factors. Eur J Respir Dis 1985, 69(Suppl. 146): A39. 